\title{
Phenomena governing uni-axial tensile behaviour of paperboard and corrugated cardboard
}

\author{
S.ALLAOUI ${ }^{*}$, Z.ABOURA $^{* *}$ and M.L.BENZEGGAGH ${ }^{* * *}$ \\ * LMSP, UMR 8106, Polytech d Orléans, 8 rue Leonard de Vinci 45072 Orléans Cedex2, France. \\ Mel: samir.allaoui@univ-orleans.fr.fax: 0033(0)238417329 \\ ** L3M, IUT de Tremblay en France Paris 8 Rue de la Râperie 93290 Tremblay-en-France, France \\ *** LRM, FRE2833, UTC, Centre de Recherche Royallieu B.P 20529 F- 60205 Compiègne Cedex, France
}

\begin{abstract}
Paperboard exhibits a complex mechanical behaviour, which is governed by several phenomena. This work proposes a contribution to the identification of these phenomena. Uniaxial tensile tests under various configurations were carried out on the paperboard and corrugated cardboard. Observations under scanning electron microscopy were thereafter done in order to identify the microscopic phenomena produced in the structure. These observations made possible to highlight the presence of damage and its various appearance mechanisms.
\end{abstract}

\section{Keywords}

Paperboard, corrugated cardboard, behaviour, damage, coating. 


\section{Introduction}

Paper materials are widely used in packing industry, media platform and number of other applications. They are made from chemical and mechanical pulp in a continuous process. The pulp is sprayed through the head box into a filter screen and dried under tension and pressure. Due to the continuous nature of the materials process, two main directions characterize paper and paperboard (figure1): transverse or cross direction denoted CD and machine direction denoted MD that corresponds to the feel orientation of the filter, therefore the privileged orientation of the cellulose fibres. To refer to out-of-plane direction (through-thickness), a third direction denoted $\mathrm{ZD}$ is introduced as depicted by figure 1 . We observe the same directions for the corrugated cardboard. Let us note that the manufacture direction of the sandwich coincides with the machine direction of the corrugated cardboard and the paperboards (figure 2).

Due to its various virtues, corrugated cardboard sandwich is the paper family the most used in packing. The more utilized configuration is the simple wall. It is composed by three paperboard components: upper layer, core and lower layer. Therefore, for a better optimization of its use, previous studies were restricted to model its elastic behaviour. Corrugated cardboard is regarded as structure $[1,2]$, sandwich [3, 4] or monolithic material [5]. All these approaches need the knowledge of mechanical properties of the corrugated cardboard components, indeed the sandwich behaviour is governed by those of its constituents.

Paper and paperboard are fibrous materials. They are built from cellulose fibres jointed by hydrogen bonds and some additional elements like talc. Due to the non-homogeneous and anisotropic nature of the paper materials, it is difficult to predict accurately the materials responses. Therefore, they exhibit complex mechanical behaviour, commonly characterized by a highly anisotropic linear elastic response (under moderate mechanical loading) and non-linear response (attributed to a plastic response) under high loading [6]. 
Under cyclic tensile test, when the paper is cycled at low strain there was little evidence of non-linear elastic behaviour. Beyond the yield stress, wide hysteresis loops appear and stress relaxation phenomena is highlighted [7]. Unloading from some point of the non-linear part of the stress strain curve further results in a permanent deformation. Tryding shows that the unloading stiffness generally coincides well with the elastic modulus [8]. Sawyer and al. [7] suggest that the molecular structure deformation mechanics are dominating the inelastic flow of paper.

This work purposes a contribution to a better comprehension of phenomena governing uni-axial tensile behaviour of the paperboard and corrugated cardboard. It will use in next works to model the global corrugated cardboard behaviour.

\section{Material}

Corrugated cardboard used in this study is single wall of type $\square \square$ An upper and lower layer and a core compose it. They are respectively denoted Recto, Verso and Well. All the constituents are composed with $100 \%$ cellulose recycled fibres. Their thicknesses are $0.26 \mathrm{~mm}$, for the Recto and the Verso and $0.21 \mathrm{~mm}$ for the Well. The total sandwich thickness is $4.1 \mathrm{~mm}$ and the flute step is $\mathrm{P}=8 \mathrm{~mm}$.

\section{Static tensile tests}

Static tensile tests were carried out on corrugated cardboard and its constituents in the two-plane direction (MD and $\mathrm{CD}$ ). The aim of these tests is to identify elastic and failure properties and highlight the different stages of their uni-axial tensile behaviour. The specimens were inspired from ISO type NF T51-034 and NF Q03-002 on the mechanical characterization of plastic materials, paper and cardboard. The most important difficulty of the tensile tests on the 
corrugated cardboard resides in the bruising of the specimen heads at the griping time. To increase the rigidity of the specimen heads, a polyester resin was injected between flutings and the cardboard skins to fill the existing emptiness. With regard to the paperboard preparation, the specimen extremities were rigidified by impregnating in the resin. This technique allows consequently avoiding the use of the special bits recommended by the norm NF Q03-002 [5].

All the specimens were conditioned at $23^{\circ} \mathrm{C}$ and $50 \% \mathrm{RH}$ for at least 24 hours before testing. The tests were conducted under $2 \mathrm{~mm} / \mathrm{min}$ crosshead speed using a sensitive load cell of $500 \mathrm{~N}$. The instrumentation used is a camera which makes possible to follow the displacements of four points positioned, on each specimen, as shown in figure 3 [9]. We note that these specimen preparations before testing were used during the various tests of this work.

Table 1 shows the elastic and failure properties obtained. For all tested materials, Young modulus and failure loads are more significant in machine direction that corresponds to the cellulose fibres and flute orientations. In the case of paperboard layers, they are twice more significant than those measured in CD.

Concerning the corrugated cardboard, it appears that the failure load in MD is equal to the sum of the maximum failure loadings of the two main layers (Recto and Verso). On the other hand, it is equal to the sum of those of the three constituent $₫$ f failures loads (layers and flute) in cross direction. The failure strain is twice more significant in CD than MD. In each direction, we note the quasi equivalence of the strains between the various constituents and the sandwich.

Characteristic stress-strain curves (figure 4 for layers and figure 5 for corrugated cardboard) show that mechanical behaviour in the two in-plane directions is composed by linear part followed-up by non-linear part. This phenomenon depends on the cellulose fibres, the hydrogen bonds and the rate of the moisture content. The nonlinearity is accentuated in the cross direction. This more marked non-linearity can be due to the fact that the paperboard mechanical 
behaviour is more governed by hydrogen bonds that are more requested in CD than the cellulose fibres.

To investigate this effect and to better understand phenomena that govern mechanical behaviour of paperboard, other mechanical tests are necessary. Therefore, the following tests were first carried out on the paperboard in order to best apprehend its behaviour. Thereafter, this permits to better understand the global uni-axial behaviour of the sandwich.

\section{a) Strain rate effect}

The viscous behaviour of paperboard can be highlighted by uni-axial tensile tests at different strain rate $(\dot{\varepsilon})$. The tests were conducted on tensile testing machine INSTRON 4411 using speed strain range going from $6 * 10-5 \mathrm{~s}^{-1}$ to $12 * 10-3 \mathrm{~s}^{-1}$, which correspond to different displacement speeds as illustrated in table 2. For each rate strain, ten specimens were tested for each paperboard in the two directions $\mathrm{MD}$ and $\mathrm{CD}$. Two instrumentations were used: extensometer and camera (figure 3).

Figures 6 to 9 present examples of stress-strain curves obtained at various strain rates request. In all cases (Well, Recto and Verso), the effect of the strain rate $(\dot{\varepsilon})$ is not negligible in both directions $\mathrm{MD}$ and $\mathrm{CD}$. Indeed, failure and yield stress increase according to strain rate. This confirms well the presence of a viscous behaviour of paperboard that appears rather at high strains rates.

This tendency is quantified in tables 3 and 4 . We note that the standard deviations are less than $7 \%$ for all the results.

At the strain rate $12 * 10^{-3} \mathrm{~s}^{-1}$, the maximum evolution of the failure stress $\left(\sigma_{\mathrm{f}}\right)$ compared to strain rate $6^{*} 10^{-5} \mathrm{~s}^{-1}$ is obtained for the skins Recto and Verso. It is about $24.92 \%$ and $30.43 \%$ respectively for the Recto skin in the machine direction and Verso skin in the cross direction. 
The smallest evolutions (about 19\%) are obtained for the Well paperboard in the two directions. The more significant evolution in the case of the skins Recto and Verso can be attributed to the behaviour of the coating used to treat the skins surfaces and which, undoubtedly, interferes on the material behaviour. Indeed, the paperboards Recto and Verso underwent a more significant coating than the Well paperboard as we will see it further.

The Young modulus evolution is more marked in the case of the Well paperboard in both directions (about 22\% between minimum and maximum rates strains request). The same rate of evolution is raised in the case of the Verso skin in the cross direction (table 4). Therefore, the linear part of the paperboard behaviour is also governed by a viscous phenomenon. If the viscous effect is well highlighted, we can wonder whether the non-linearity beyond yield stress is due only to this phenomenon, or other additional phenomena intervene in the process. In order to answer this interrogation, other tests are necessary.

\section{b) Strain recovery}

The goal of the strain recoveries tests is to check the existence or not of a permanent deformation after unloading. The tests were carried out on uni-axial dynamic testing machine INSTRON 1341, with a cell of $1 \mathrm{KN}$. This machine controls either in strain or in stress rates.

The specimens were loaded in stress controlled with a stress rate of $\dot{\sigma}=0,5 \mathrm{MPa} / \mathrm{s}$. Once in non-linear part, the specimens were unloaded to a value near zero without reaching zero (in order to avoid the buckling) with the same stress rate. Then, they were heeded at a fixed stress during 24 hours. Throughout the test, the strain was measured by an optical method.

Figures 10 and 11 present examples of loading-unloading-holding response of the Verso skin in MD and Recto layer in CD. Specimen of Verso skin was requested, until a strain of 2.8\% (Figure 10). After unloading and load holding, the material covers a strain of $1.53 \%$ in 3 hours of 
time. Beyond, the strain covers is unimportant, less than $0.03 \%$ during 21 hours (Figure 12). At the end of the test, the residual strain is about $1.27 \%$. Therefore, paperboard recovers $55 \%$ of the initial strain.

For the skin Recto, it was requested in the direction CD until a deformation of $2.05 \%$ (Figure 11). After unloading and load holding, the strain recovered is about $1.47 \%$, during 3 hours. After 24 hours of holding, the residual strain is about $0.59 \%$ and the covers strain represents $71 \%$ of the initial strain. Note that the recovered strain is more important in the Cross direction, due to the fact that the phenomenon is mainly managed by the connections inter fibres, whereas in the machine direction the fibres govern the behaviour.

Loading-unloading-holding tensile tests carried out on the skins, in the two directions, revealed a residual plastic strain. Thus, non-linearity of the paperboard is governed by a viscoplastic phenomenon. The slopes of unloading are curved. This indicates the presence of energy dissipation, so a loss of stiffness. This dissipation can be due to the presence of a damage coupled with the viscoplastic phenomenon. The next step of this study concerns the checking and quantification of the damage presence by using cycling loading tests.

\section{Cyclic loading tensile tests}

Generally, the quantitative evaluation of damage is done through the evolution of an elastic variable, which characterizes the studied phenomenon. For the needs for this study, this variable is the Young modulus. Cyclic tensile tests were carried out on ten specimens for each paperboard in the two directions. The specimens were loading and unloading at the same strain rate $\left(\dot{\varepsilon}=24 * 10^{-5} \mathrm{~s}^{-1}\right)$. The increments of loading were fixed at $20 \mathrm{~N}$ for the machine direction and $10 \mathrm{~N}$ for the cross direction. Once the data acquisition made, the parameter $\mathrm{D}$ was established for each level of loading as follows: 


$$
D=\left(1-\frac{E_{d}}{E_{0}}\right) \times 100
$$

Where $E_{0}$ is the Young modulus measured in initial linear part and $E_{d}$ the Young modulus measured for each level of loading, during the unloading beyond the zones with stronger nonlinearity. The measurement domain was established between $0.85 \%$ and $0.25 \%$ of the reached load.

Parameter D allows following the evolution of the material behaviour. It includes the damage parameter, but also taking into account the presence of a viscous phenomenon. This parameter cannot be used as a damage parameter in a modelling approach.

Figures 13 and 14 illustrate the examples of Verso skin behaviour, in machine and cross directions, during the loading-unloading tensile tests. During the first cycles, at low stress, there is no evidence of non-linear elastic behaviour and residual strains. Thus, the skins have a reversible linear behaviour. By increasing the increment of the load, in nonlinear field, loops of hysteresis appear synonymous with energy dissipation. These loops become more open while advancing in the nonlinear field.

An average of the evolution curves of the parameter D is represented on Figure 15. The stiffness loss occurs earlier in the cross direction than in MD. This phenomenon starts at a stress of $10 \mathrm{MPa}$ in $\mathrm{MD}$ and $3 \mathrm{MPa}$ in $\mathrm{CD}$ (Figure 15). Moreover, the evolution of parameter D, which is represented by the curves shape, is more significant in cross direction than in machine direction.

The maximum value reached by the parameter $\mathrm{D}$ in the case of Recto and Verso skins (Upper and Lower layers) is about $15 \%$ in both in-plane directions. On the other hand, in the case of Well paperboard used for the flute, stiffness loss is twice more significant in the machine direction than the cross direction (respectively $16.6 \%$ and $7.4 \%$ ).

This difference in the behaviour between the skins (upper and lower) and the paperboard of the flute can be due to the coating treatment undergone by the upper and lower skins. This 
surface coating improves printing quality on external skins of the corrugated cardboard packing. Therefore, it is little used for the flute paperboard. Indeed, it is denoted that the coating on the Recto and Verso skins, is about few tens of microns and is present on all the skins surfaces (Figure 16). A perpendicular sight of the treated surface reveals this facing with the detriment of the cellulose fibres that are not visible. On the other hand, this coating is weak $(<10 \mu \mathrm{m})$ for the Well paperboard and its presence is not homogeneous on all the skin face (Figure 17). The cellulose fibres are well distinguished on the treated face. This film used for coating is made up of polymeric materials. It probably attenuates the damage of the two skins Recto and Verso, which is not the case of the paperboard Well that arrived at failure rather quickly.

Nevertheless, whatever the components of the sandwich, a significant loss of rigidity is observed contrary to precedent works [8] where the stiffness under unloading, from each point on the non-linear field, coincides well with the elastic modulus. This pushes us to believe that there is presence of damage phenomenon that occurs in material. In order to confirm this presence and the moment of its apparition, uni-axial tensile tests under scanning electron microscopy (SEM) were carried out.

\section{Relaxation tensile tests under SEM}

To be able to note the damage presence and its coupling with viscoplasticity, in-situ tensile tests with holding at fixes strains under SEM were carried out on the paperboard (figure 18). The load cell capacity is $300 \mathrm{~N}$. It was assembled inside the SEM and then connected to an acquisition system. The minimal length between the two jaws of the device is $10 \mathrm{~mm}$ and the maximum race is $10 \mathrm{~mm}$. Micro specimens were cut out for the three paperboards in the two directions MD and CD. The Length of the useful part between jaws of specimens is $10 \mathrm{~mm}$ and their width is $5 \mathrm{~mm}$. Paperboard being a no conducting material, the specimens underwent a 
metallization with a film of gold before testing in order to ensure conductivity. Thereafter, they were assembled on the device inside the SEM, and tested with rate strain control of $12 * 10^{-6} \mathrm{~s}^{-1}$. In order to highlight the effect of stress relaxation and its appearance, each test was carried out with holding at various strain levels. During these material relaxations, fractographies were taken to show the nature of damage. Mechanical parameters obtained by theses tests will not be exploited because of the scale effect. Only physical phenomena will be considered.

\section{a) Results and discussions}

Figure 19 illustrates the example of Well paperboard behaviour during relaxation test under SEM according to cross direction. Fractographies corresponding at each strain holding are shown. At the first one, corresponding to the linear field of curve, stress falls synonymous of relaxation. On the other hand, the stress relaxation in linear part is weak in the machine direction (Figure 20). This observation consolidates the results of precedents tensile tests at various rates strains control. It confirms the presence of viscoelastic phenomenon at the elastic phase. This phenomenon is more significant in the cross direction than in the machine direction. This is due to the fact that the hydrogen bonds between fibres, which can have a viscous behaviour, are requested more in $\mathrm{CD}$.

Stress relaxation of paperboard increases with the increase of load level. This is due to the viscoplastic behaviour, which becomes more important in the nonlinear phase. As previously, these stress relaxations are more significant in the cross direction than in the machine one.

For the Well paperboard in $\mathrm{CD}$, the damage intervenes with the second strain holding $(\varepsilon=0.23 \%)$ beyond the linear part. Microscopic cracks appear locally. By increasing load level, microscopic cracks appear in greater number on the entire specimen surface as we can notice it at strain $\varepsilon=0.89 \%$ on Figure 19. In fifth holding, the starting of macroscopic crack appears 
between the diffuse microscopic cracks. This crack increases and another one appears with the following holding. The final failure of material occurs according to the macroscopic crack appeared in first and according to a cross-section.

Like in the cross direction, microscopic cracks appear at the second strain holding $(\varepsilon=0.36 \%)$ beyond the linear phase on specimens loaded in machine direction. We note a presence of few microscopic cracks located in only some areas of the specimen in spite of the strain holding in the nonlinear part (Figure 20). The material failure intervenes abruptly in an area, which is not very reached by the damage, other that which saw germinating the most microscopic cracks.

\section{b) Damage mechanisms}

This part of the article relates the damage phenomena observed under the microscope and consequently details the preceding phenomenological explanations. At first holdings, the areas where appear first microscopic cracks were located. Thereafter, pictures of these areas were taken at each holding, in order to follow the microstructure evolution.

Figure 21 presents an example of damage evolution of specimen until failure in $\mathrm{CD}$. The first photography (figure 21 a) shows many and diffuses microscopic cracks on the specimen. One of the explanations to this phenomenon is that damage, in direction $\mathrm{CD}$, occurs in the form of failure of the bonds between fibres. These bonds control the behaviour of paperboard in cross direction and are less rigid than cellulose fibres. These micro cracks coalesce to generate a macro crack, which appears in bottom of the sample. It is obvious that the edge effect is partly responsible for the localization of this macro crack. The figure $21 \mathrm{~d}$, zoom of the figure $21 \mathrm{a}$, confirms this report and brings an additional explanation. Indeed, it appears that the effect of cutting and the radius curvature of the specimen take part in the failure initiation. This 
macroscopic crack becomes extensive until causing the failure (figure $21 \mathrm{~b}$ and c). On all the tested specimens, failure intervened according to the first appeared macroscopic crack.

Figure 22 shows an example of crack from its appearance to the failure for specimen tested in cross direction. Evolution of the crack occurs while skirting fibres. Badly directed fibres being on its trajectory are broken (figure $22 \mathrm{~b} \varepsilon=1.01 \%$ ). Figure $22 \mathrm{~d}$ shows an example of the presence of badly directed fibres broken or torn off in-depth of the paperboard. The final failure intervenes according to a cross-section of the specimen. These failure facieses are in agreement with those found during tensile tests off-axis carried out in precedent study [10].

Contrary to the paperboard behaviour in cross direction, where the microscopic cracks are diffuse, in the case MD they are really localized near the edges of the specimen (figure 23). Here again, the effect of the specimen size and the nature of the cutting play a part in the crack initiation. (figure 23b). The first macroscopic crack (high part of photography b) appears in one of these zones and extends along the section. At the same time, another crack starts (down part of photography $b$ ). This second crack is propagated more quickly than the first one until causing the failure (figure $23 \mathrm{c}$ and $\mathrm{d}$ ). The final failure occurs according to a crack, which found the most direct way of fibres skirting therefore requiring less energy. This phenomenon is due to the damage mechanisms governing the behaviour of paperboard in this direction. Indeed, the crack is propagated in the transverse direction of cellulose fibres. Therefore, fibres failure is the prevalent damage mechanism in paperboard tested in machine direction. Crack develops by first circumventing the fibres and then after by breaking them. That is what explains its sinuous shape [10]. On the whole of the tested specimens, the section where occurs the final failure could not be predicted precisely.

Therefore, damage of the paperboard intervenes in several forms. We can note fibre skirting (Figure 24a), fibres failures (figure 24b) or even the coating damage (figure 24c). These 
mechanisms are found in the two in-plane directions (MD and CD), but with more or less significant proportions.

\section{Cyclic loading tensile tests on corrugated cardboard}

Several complex phenomena coexist on paperboard behaviour. Therefore, after having highlighted them, it would be interesting to know their influence on the corrugated cardboard behaviour. For this reason, cyclic tensile tests were carried out on the sandwich. Static tensile machine INSTRON 4411 is used.

Ten specimens were tested in each in-plane direction of the material. To measure strains, each specimen was instrumented by extensometer and camera and then loaded and unloaded with the same strain rate $\left(\dot{\varepsilon}=24 * 10^{-5} \mathrm{~s}^{-1}\right)$. Increments of loading were fixed at $20 \mathrm{~N}$ for the machine direction and $10 \mathrm{~N}$ for the cross direction. For each test, load-strain tensile was plotted. Thereafter parameter D, considering previously, was established for each load level.

The Corrugated cardboard behaviour during these tests is similar to that of the paperboard in the two directions (Figure 25 and 26). During the first unloading, at low strains, there is not evidence of non-linear elastic behaviour and residuals strains. By increasing increment of load, in nonlinear field, loops of hysteresis appear synonymous with energy dissipation. These loops become more open while advancing in the nonlinear domain.

Evolution of the parameter D, representing the evolution of mechanical behaviour of the sandwich, was established for each test. An average of these evolutions in the two directions is represented on figure 27. The stiffness lost is earlier and its evolution is more significant in the cross direction. Its starting occurs towards a stress of $0.4 \mathrm{MPa}$ in this direction and $0.7 \mathrm{MPa}$ in MD. The value of $\mathrm{D}$ in the direction MD is about $20 \%$. It is very near to that of the paperboards (around 16\%). The request of the corrugated cardboard in this direction is distributed primarily 
on the external skins [6], which explains this report. The small difference can be due to the interference of the interfaces skin-flute on sandwich behaviour. The damage of these interfaces, which are rigid, generates a local damage of the paperboard. These interfaces intervene more in cross direction, where they are requested at the same time than the skins and the flute. This explains why the parameter D is twice more significant than those of paperboards, because their damage is added to that of the rigid interfaces.

These observations carry out us to think that mechanical behaviour of corrugated cardboard, in uni-axial tensile, is controlled by the skins behaviour, even if it would be appropriate to add a small effect of the core and the interfaces skin-flute.

\section{Conclusions}

Due to its particular microstructure, paperboard presents a complex tensile behaviour governed by several phenomena. Tests carried out in this study confirm the presence of viscoelastic phenomenon, in the linear part, and viscoplastic one in the non-linear part. In addition, damage of paperboard was highlighted through cyclic and relaxation tensile tests. The behaviour of this material is thus more complex compared to what is described in literature, since this coexistence is synonymous with a coupling of viscosity-plasticity-damage.

The damage, whose evolution and importance are more increased in the cross direction, was highlighted very early during the tests. It is governed mainly by hydrogen bonds between cellulose fibres but also by fibres skirting. Moreover, cyclic tests showed the effect of the coating on damage evolution. In the case of corrugated cardboard sandwich, this complexity is increased with the interference of the rigid interface skin-flute. Nevertheless, it is not aberrant to think that the global behaviour remains to be controlled by the skins that reduce the structure effect on tensile test. 
From a phenomenological point of view, the works in progress relate to the environmental effect on the mechanical behaviour. Whereas, from a modelling point of view, future works will try to approach, with the sight of the results of this study, the prediction of tensile behaviour beyond elasticity of corrugated cardboard, by taking into account the complex mechanical behaviour of its constituents. .

\section{References}

1 M. E. Biancolini, Evaluation of equivalent stiffness properties of corrugated board, Composite structures, 2005, Vol. 69(3), p.322-328.

2 L. Beldie, G. Sandberg, L. Sandberg, Paperboard packages exposed to static loads-finite element modelling and experiments, Packaging technology and science, 2001, Vol. 14, p.171-178.

3 T. Nordstrand, Parametric study of the post-buckling strength of structural core sandwich panels, Composite structures, 1995, Vol. 30(4), p.441-451.

4 A. Allansson, B. Svärd, Stability and collapse of corrugated cardboard; numerical and experimental analysis, Masters dissertation, Lund University, Sweden, 2001.

5 Z. Aboura, N. Talbi, S. Allaoui, M.L.Benzeggagh, Elastic behavior of corrugated cardboard: experiments and modeling, Composite Structures, 2004, Volume 63, Issue 1, p. $53-62$.

6 Baum, G. A., Subfacture mechanical properties. In Transactions of the Fundamental Research Symposium, ed. C. F. Baker. Pira International, 1993, Vol. 1, pp. 1-127

7 Sawyer J. P. G., Jones R., Mc Kinlay P., An experimental description of the response of Paper, Composite Structures, 1996, Vol 36, pp. 101-111 
8 Tryding, J., In-Plane Fracture of Paper, Dissertation, Division of Structural Mechanics, Lund University, Lund, Sweden. , 1996

9 S.Allaoui, Z.Aboura, M.L.Benzeggagh, Effect of the environmental conditions on the mechanical behaviour of the corrugated cardboard, Composite Science and Technologie, 2006, Special issue JNC14, accepted.

10 S. Allaoui, Study and modelling of behaviour of the corrugated cardboard sandwich structure, Phd report, Université de technologie de Compiègne, Compiègne, France, 2005. 

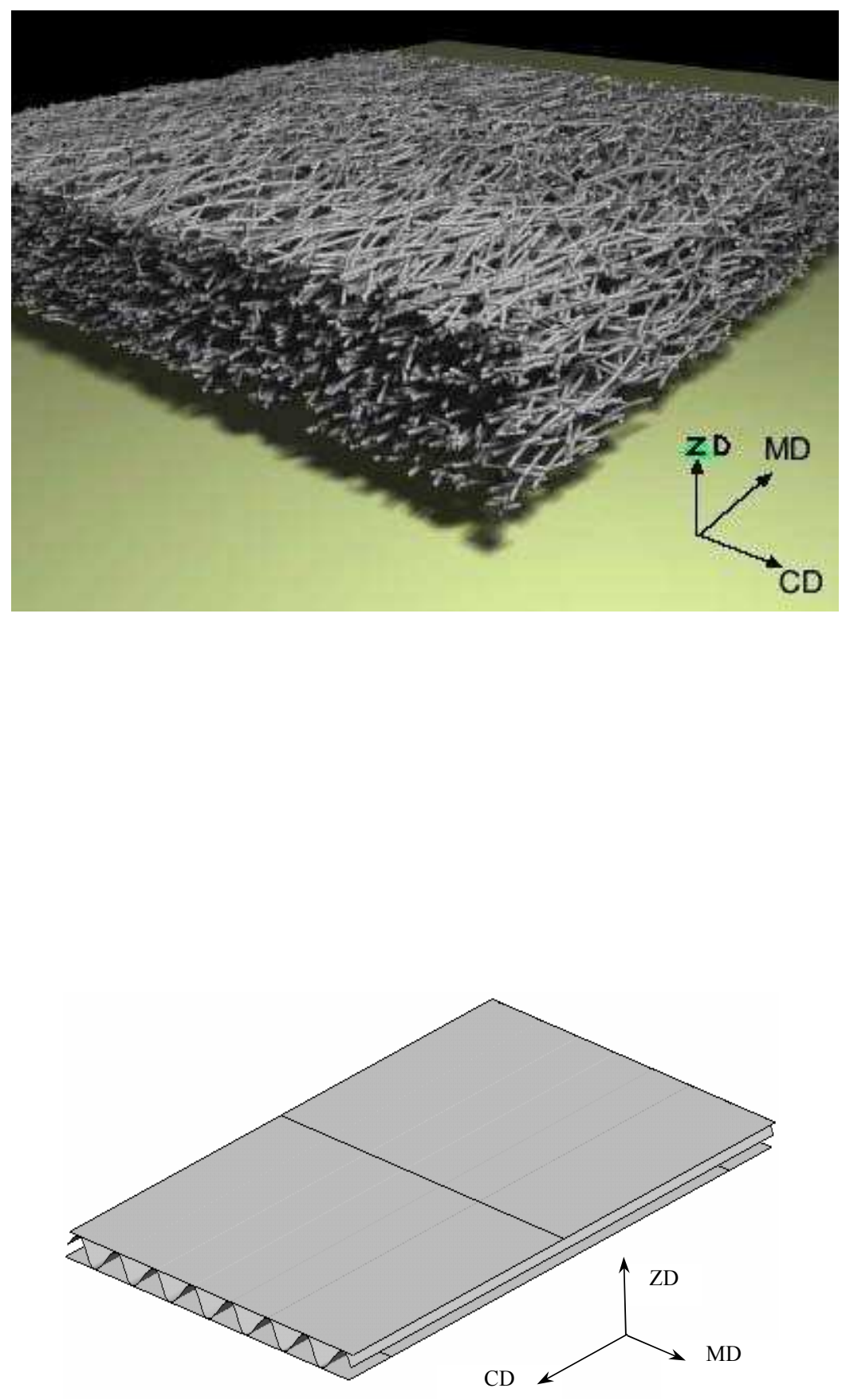

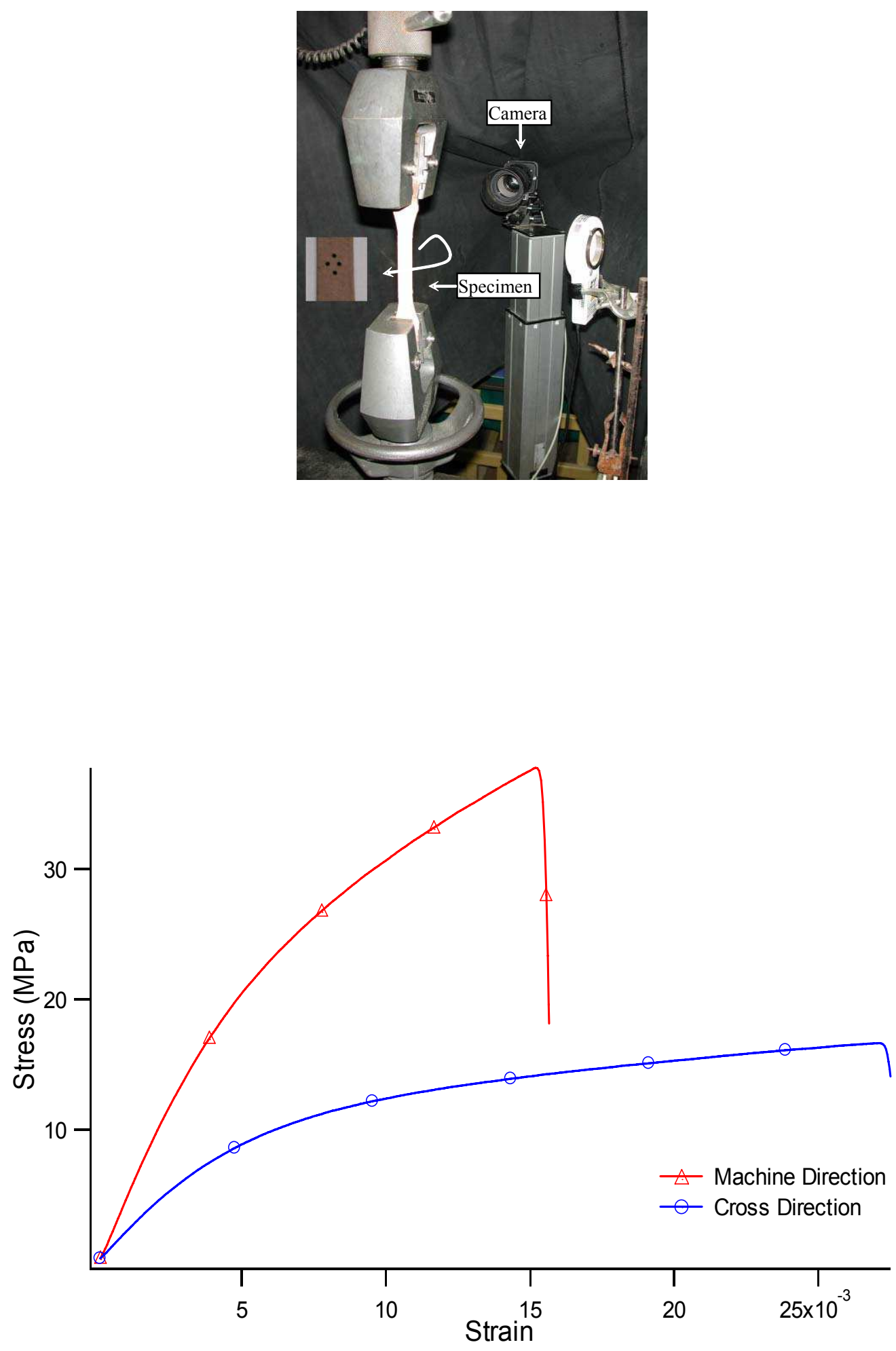

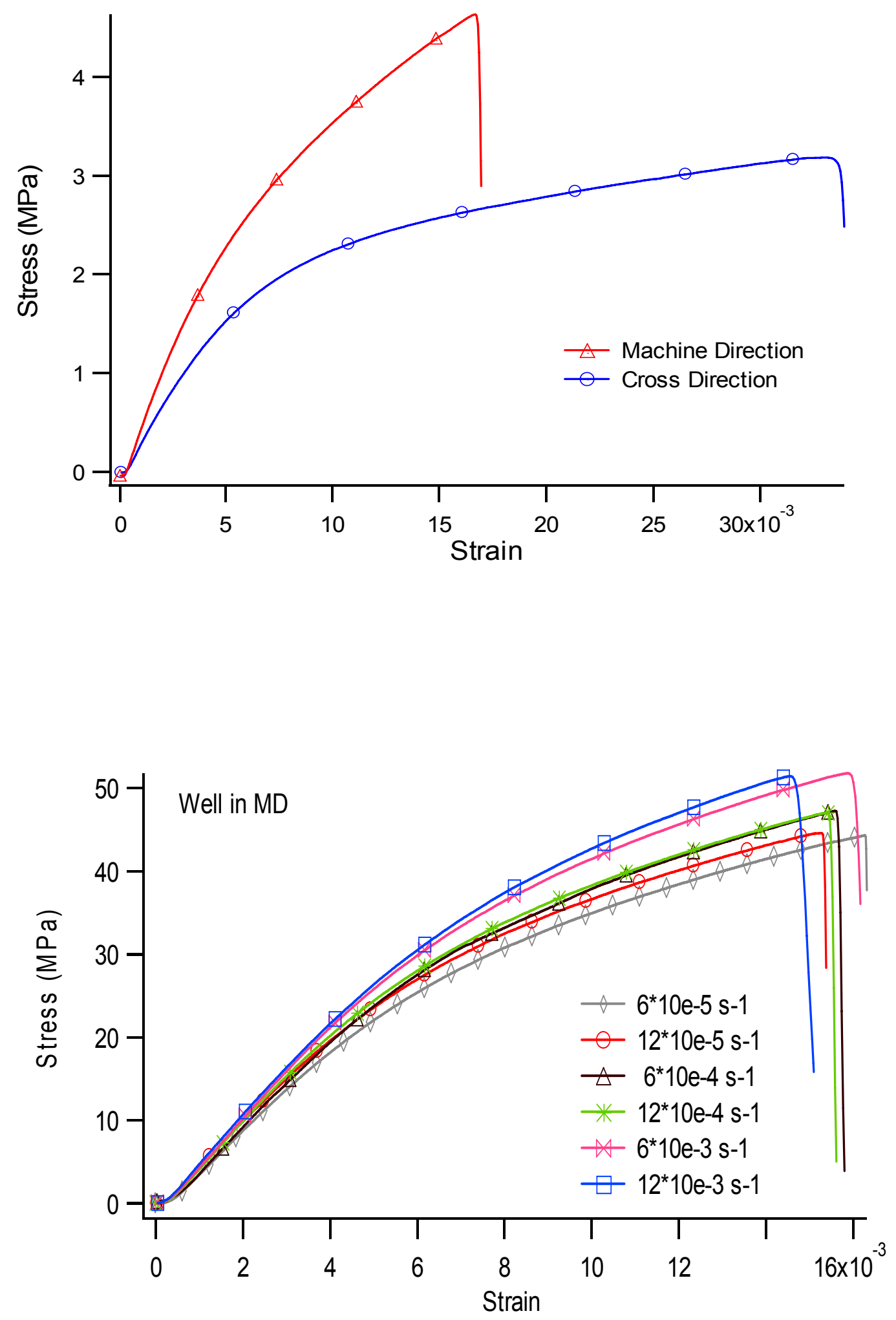

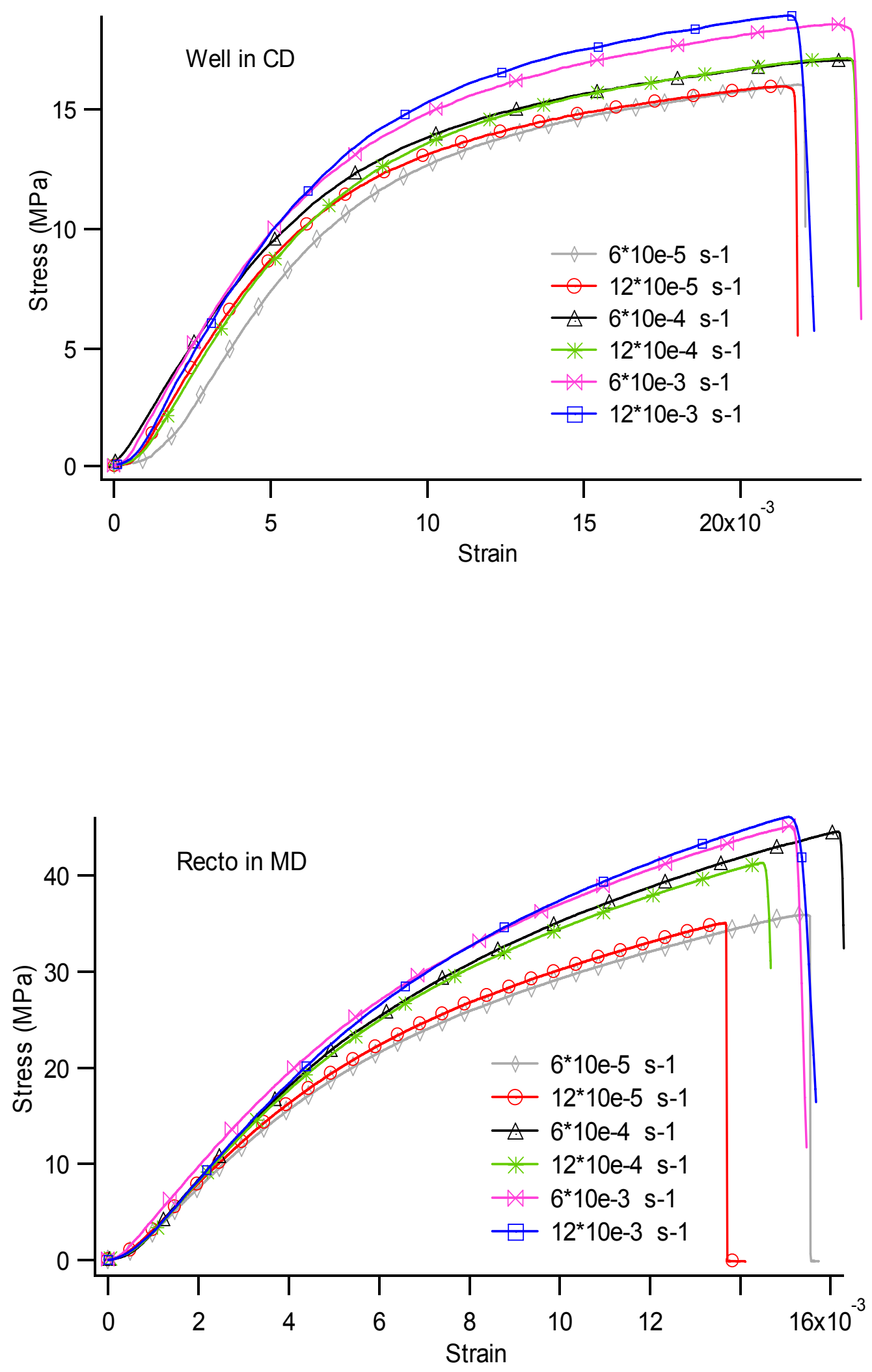

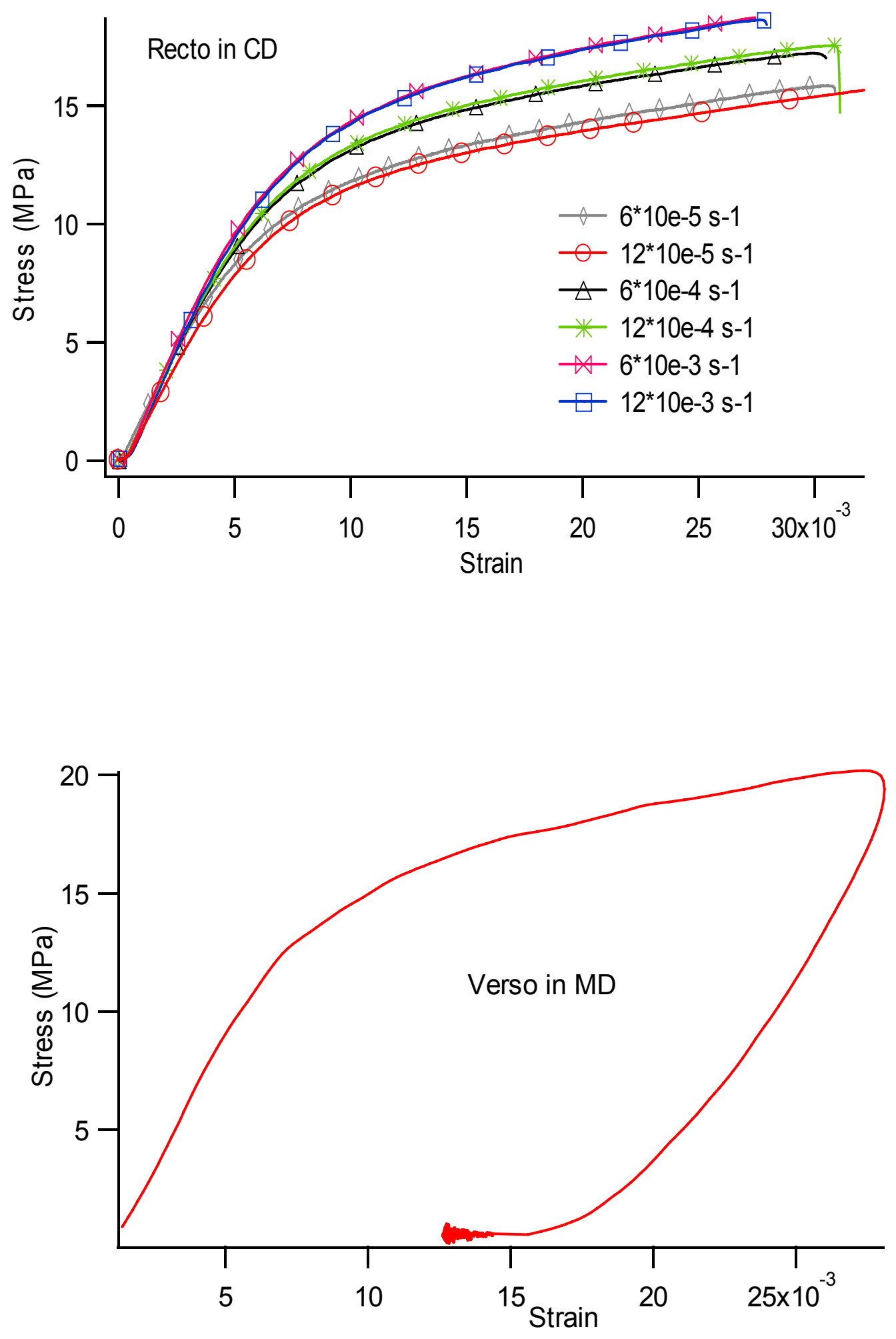

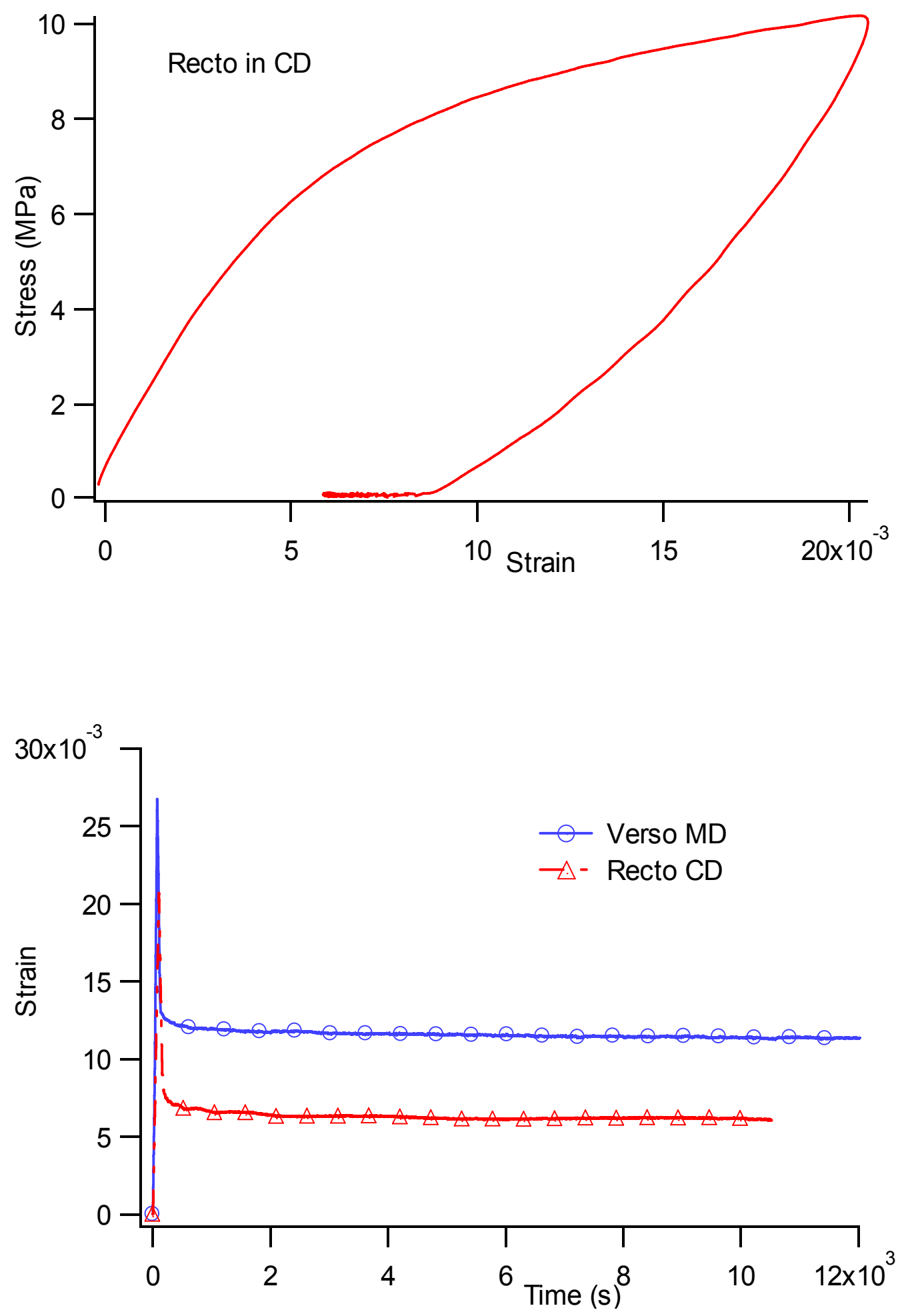

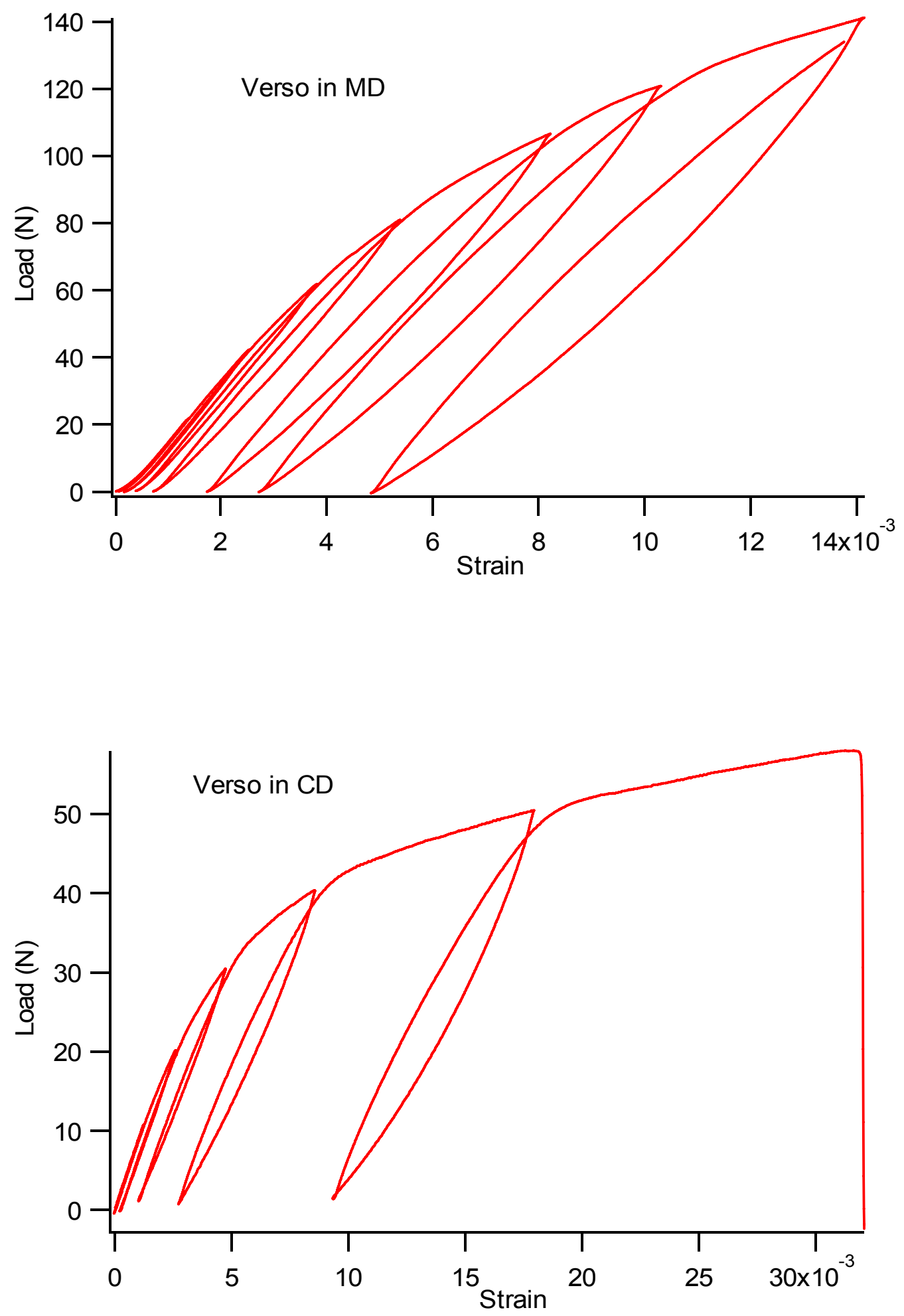

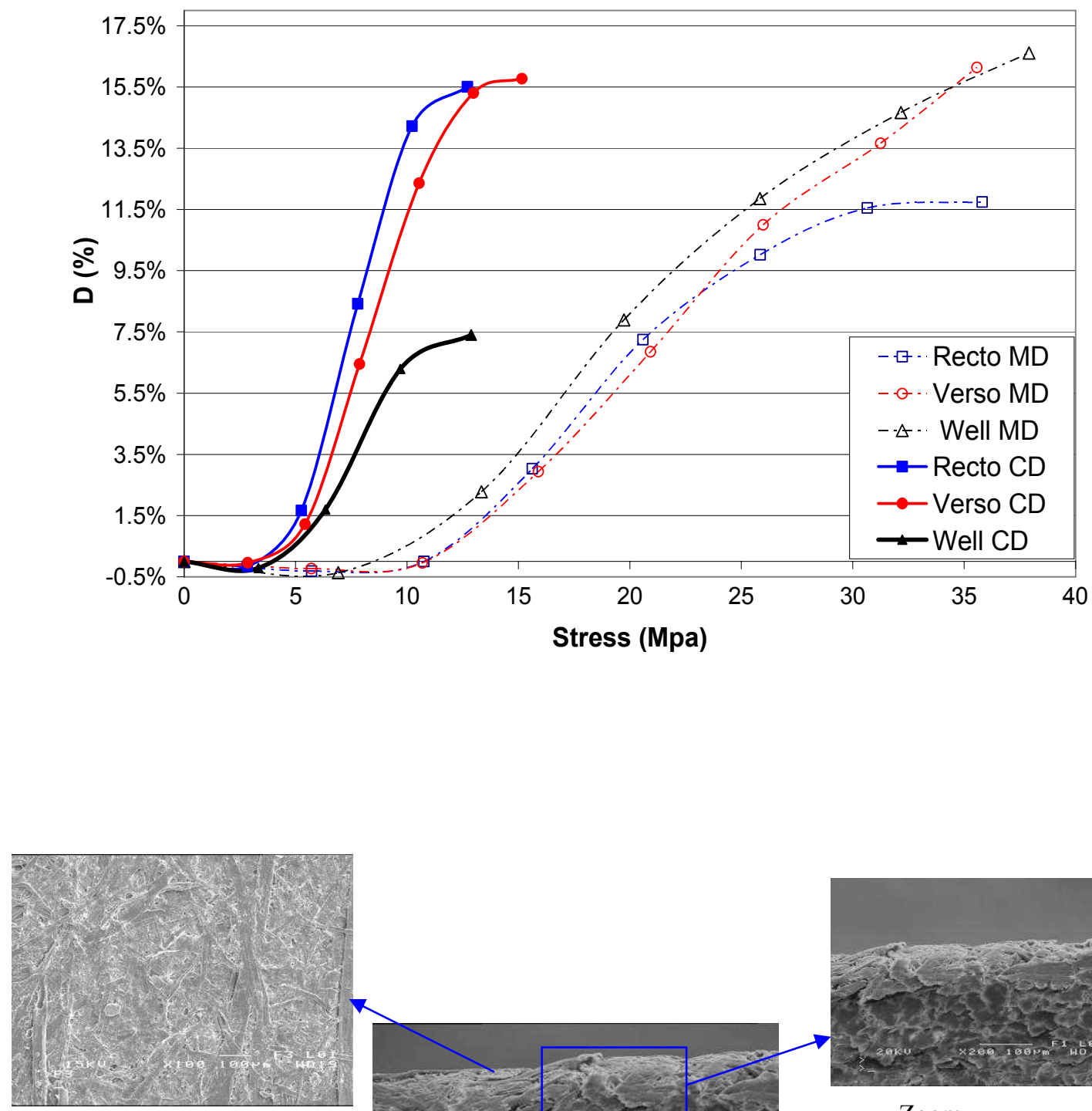

Treated Face
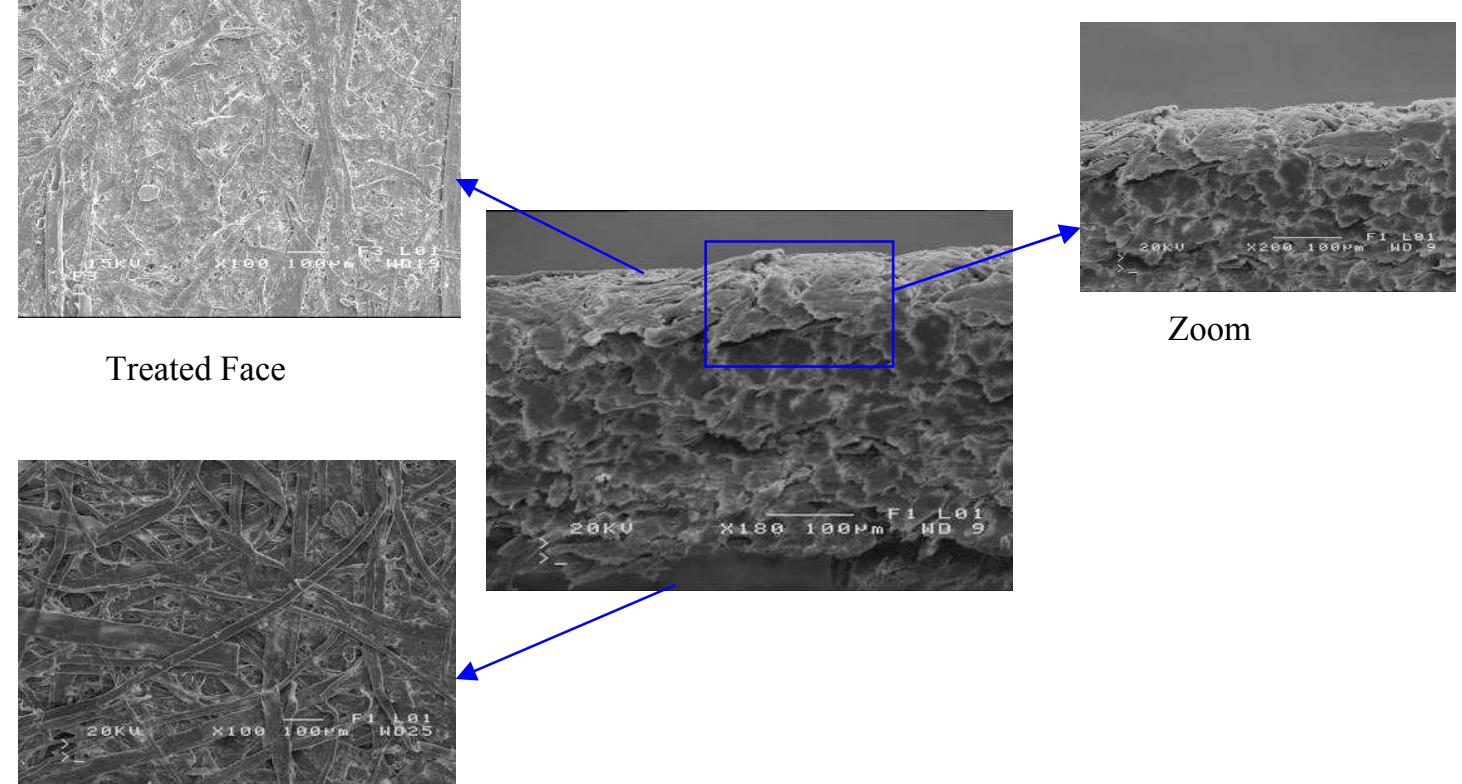

Zoom

Untreated face 


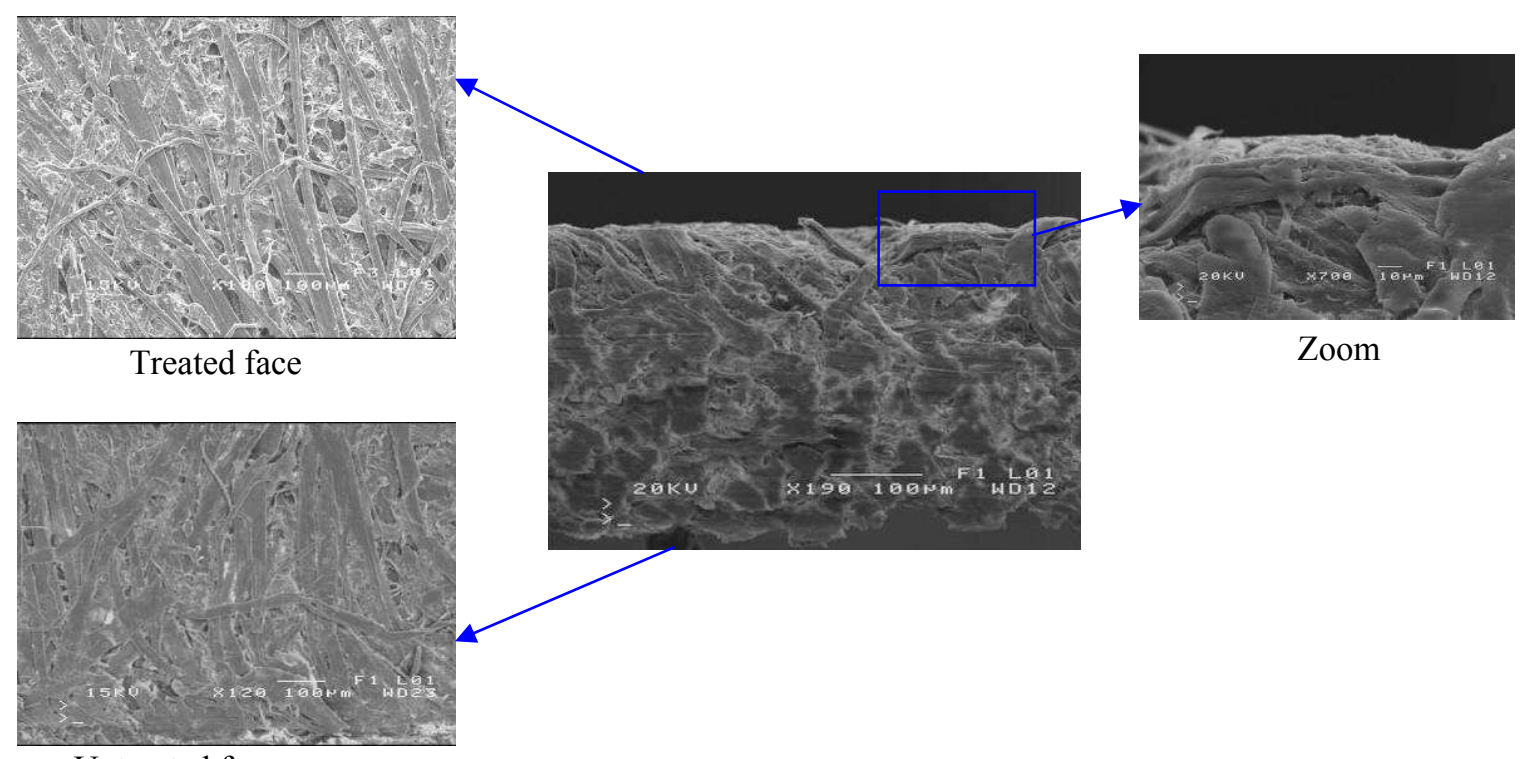

Untreated face
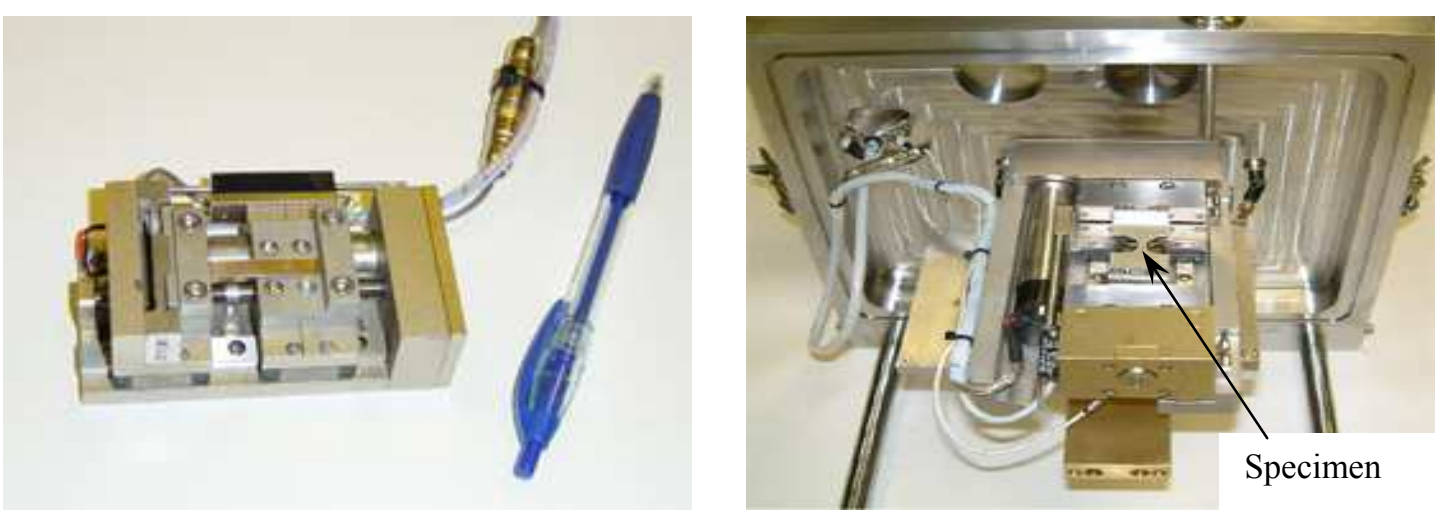


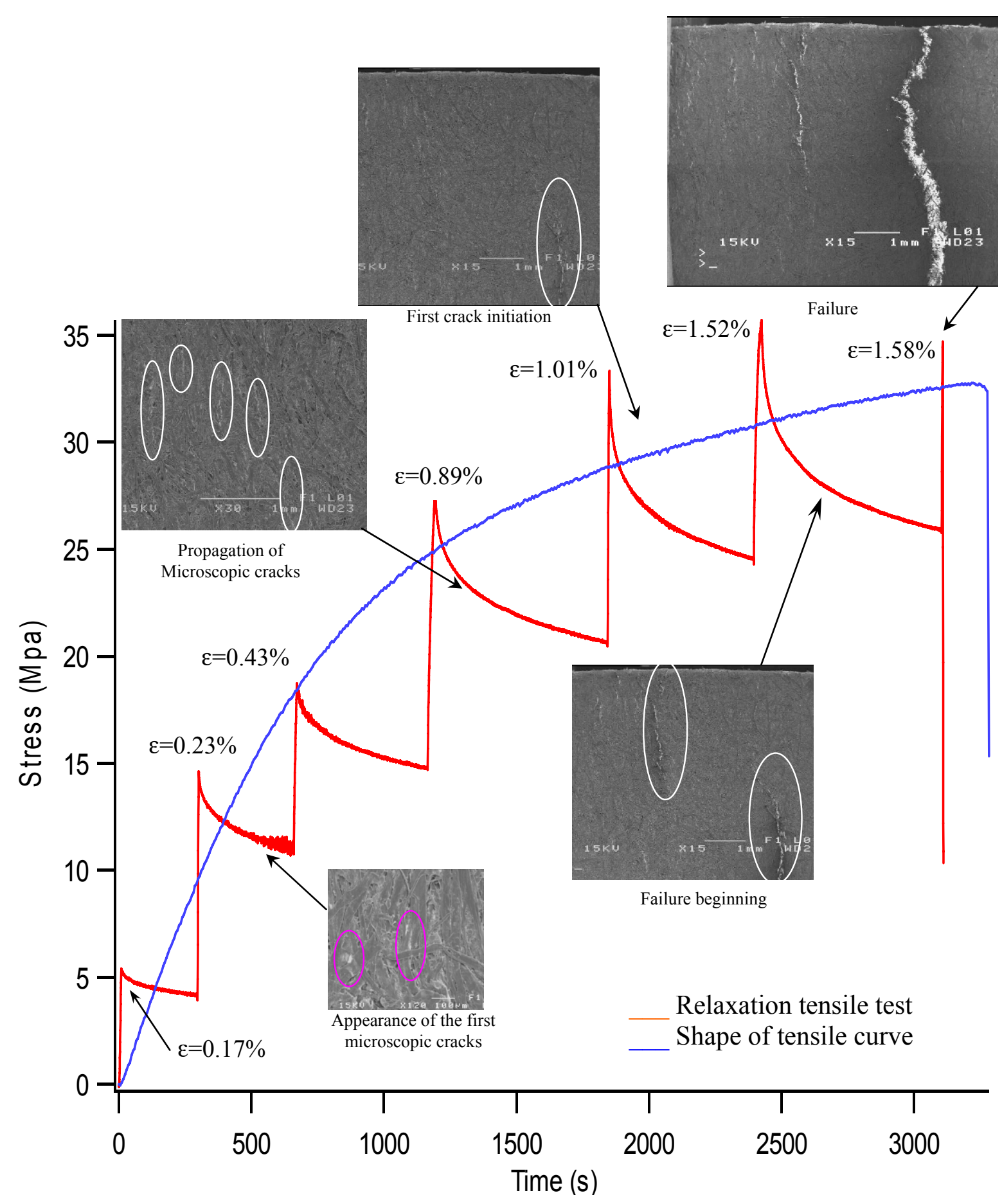




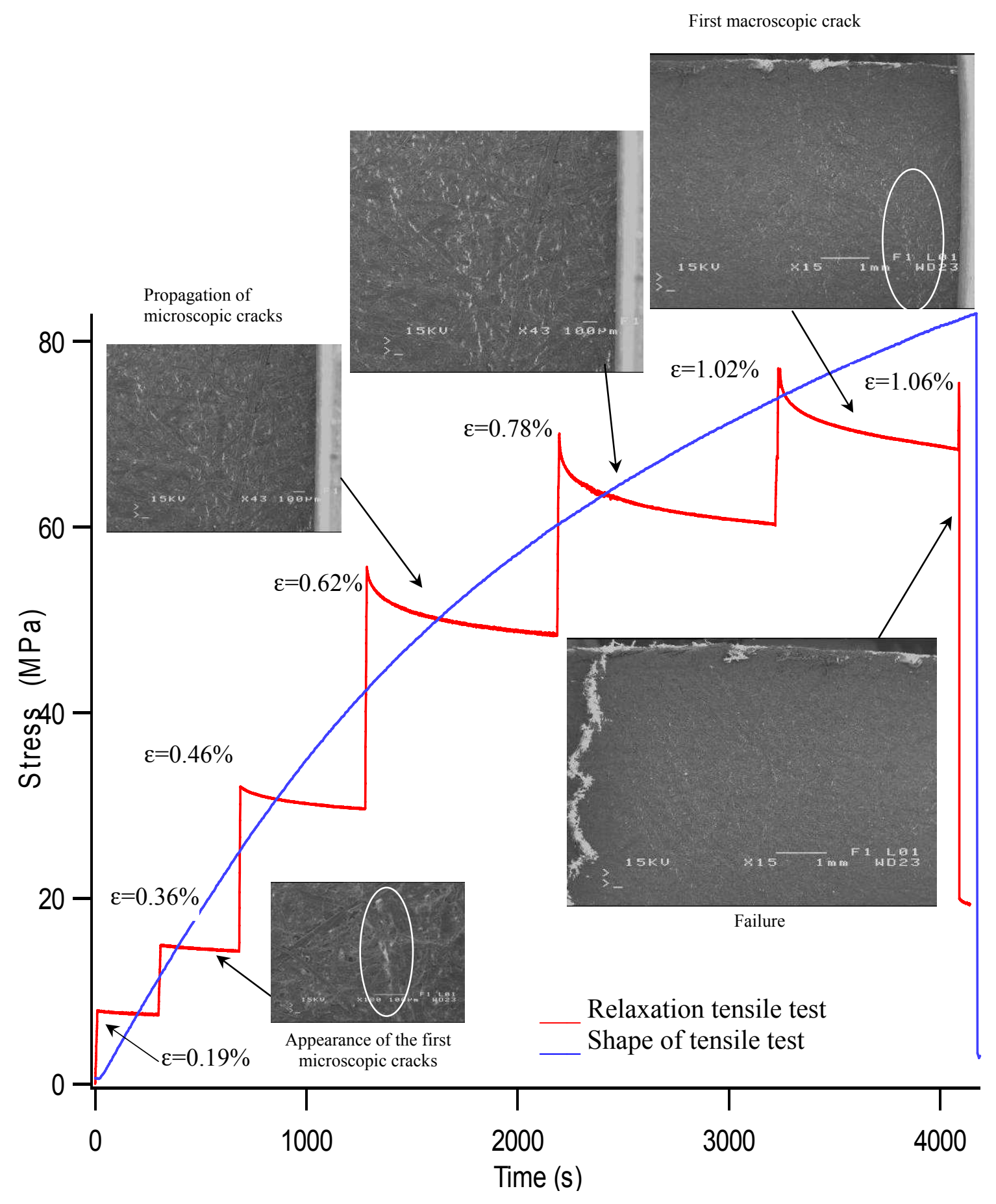




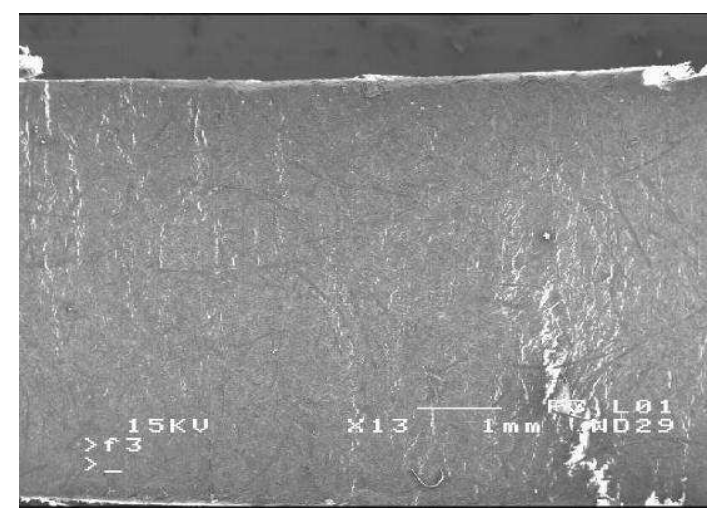

a

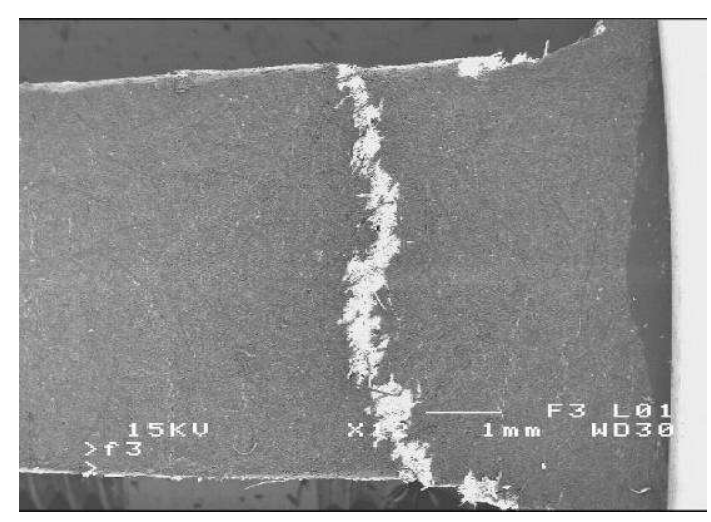

c

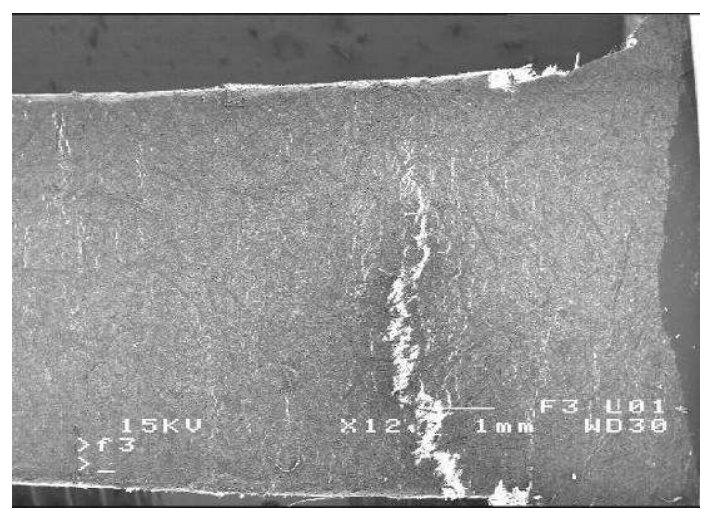

b

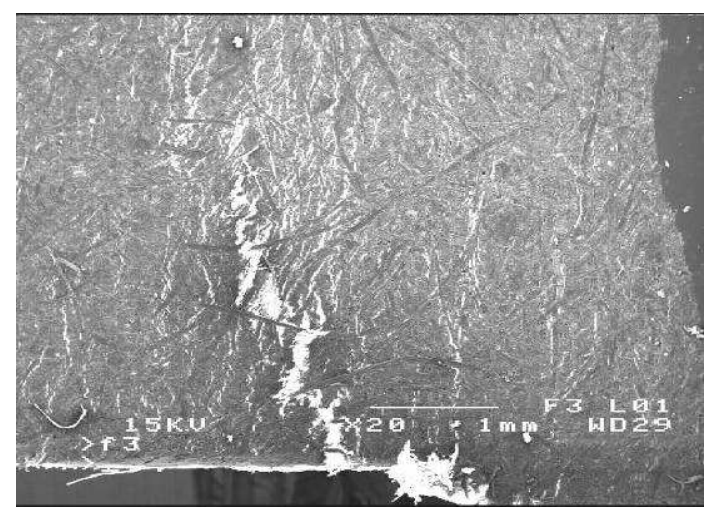

d (zoom of a) 


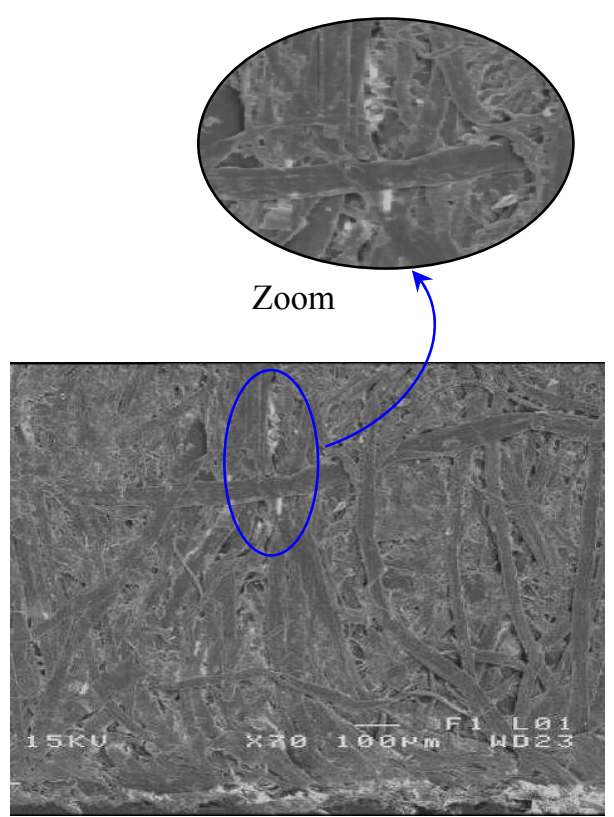

(a) : Holding at $\varepsilon=0.43 \%$

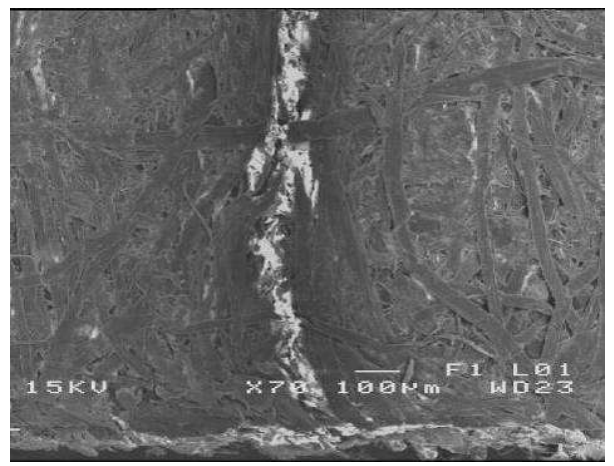

(c): Holding at $\varepsilon=1.52 \%$

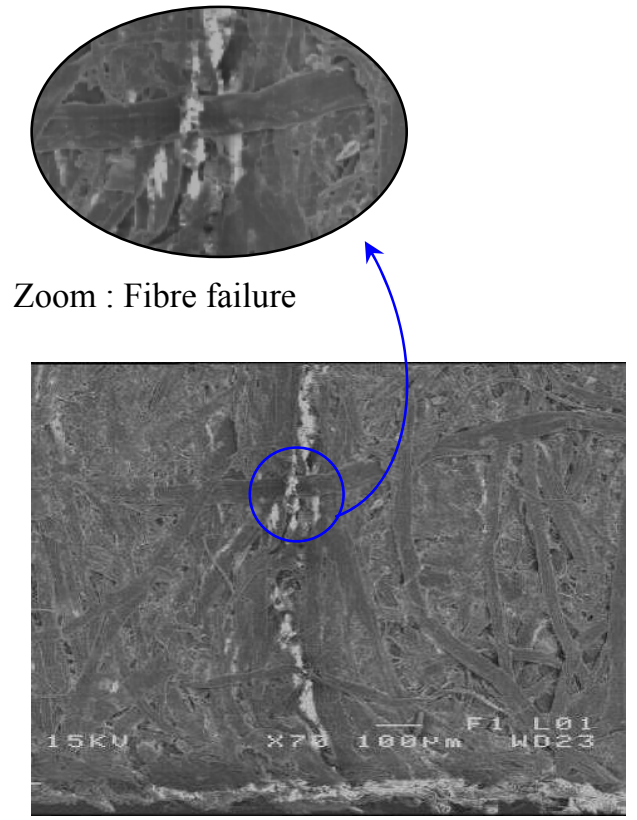

(b): Holding at $\varepsilon=1.01 \%$

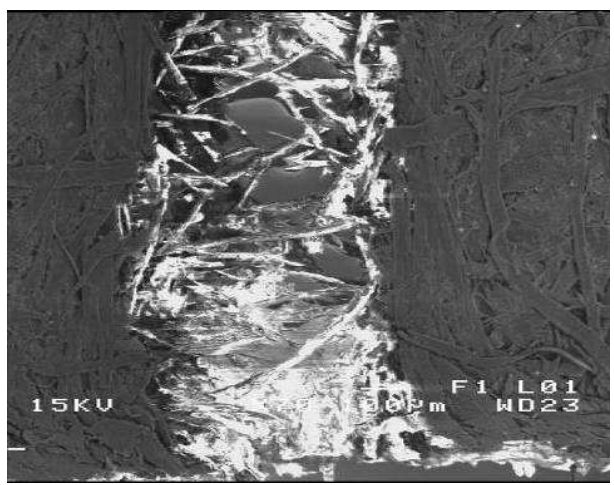

(d) : Failure 


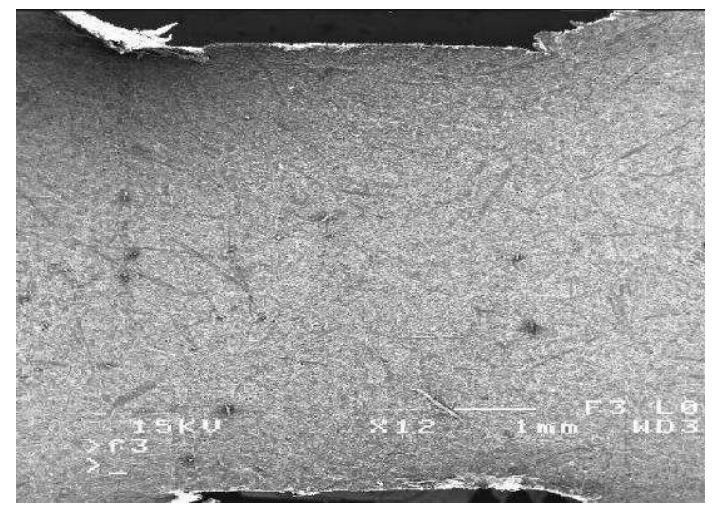

a

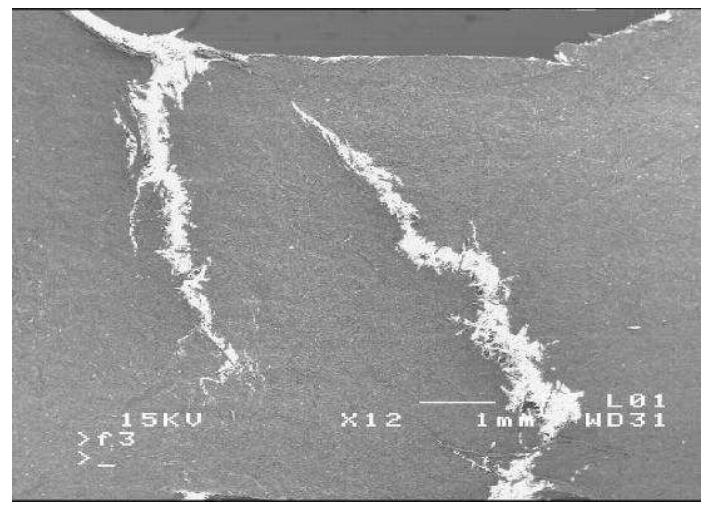

c

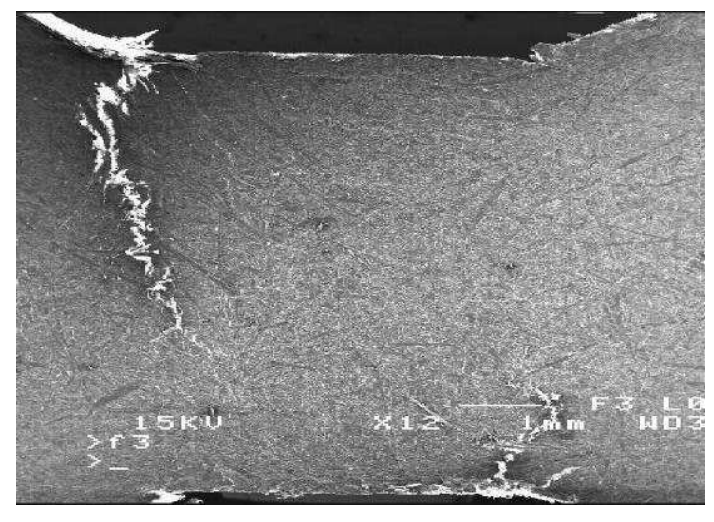

b

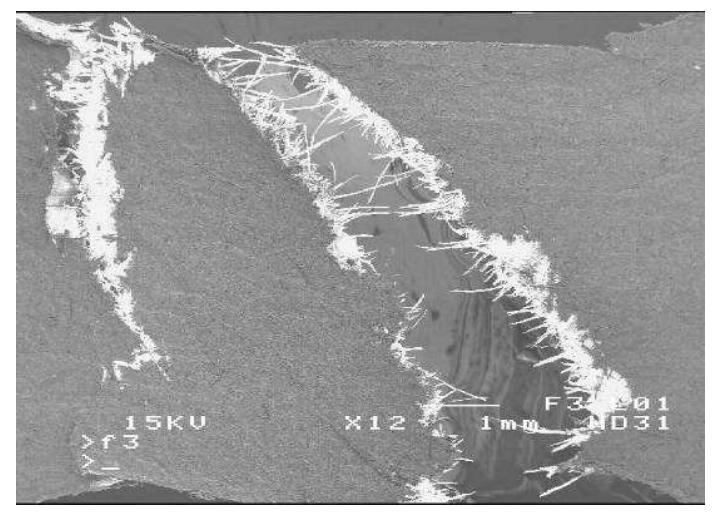

d 


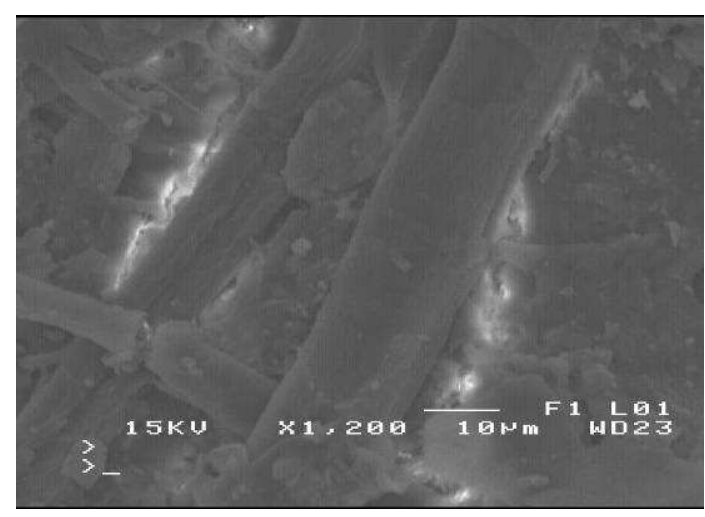

(a) : Fibres skirting

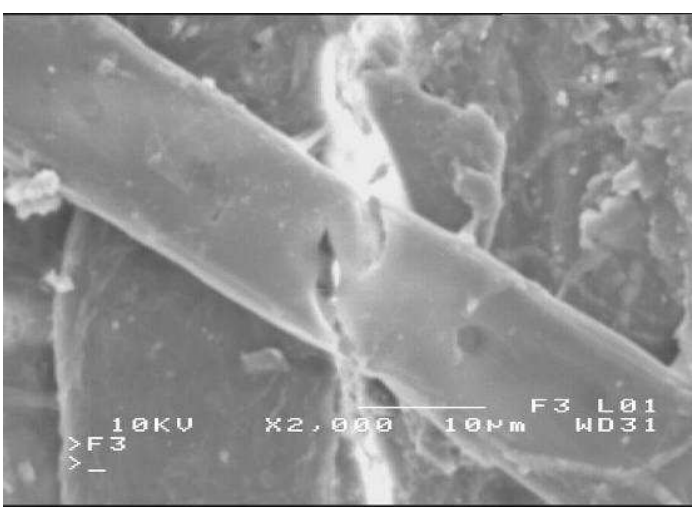

(b) : Fibres failure

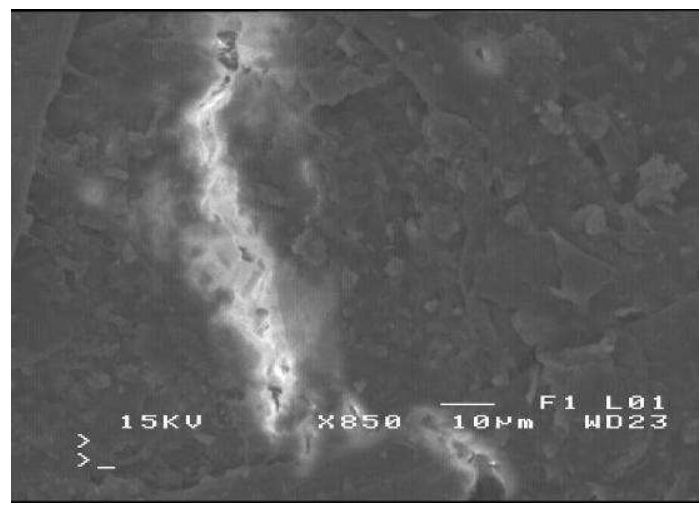

(c) : Coating damage

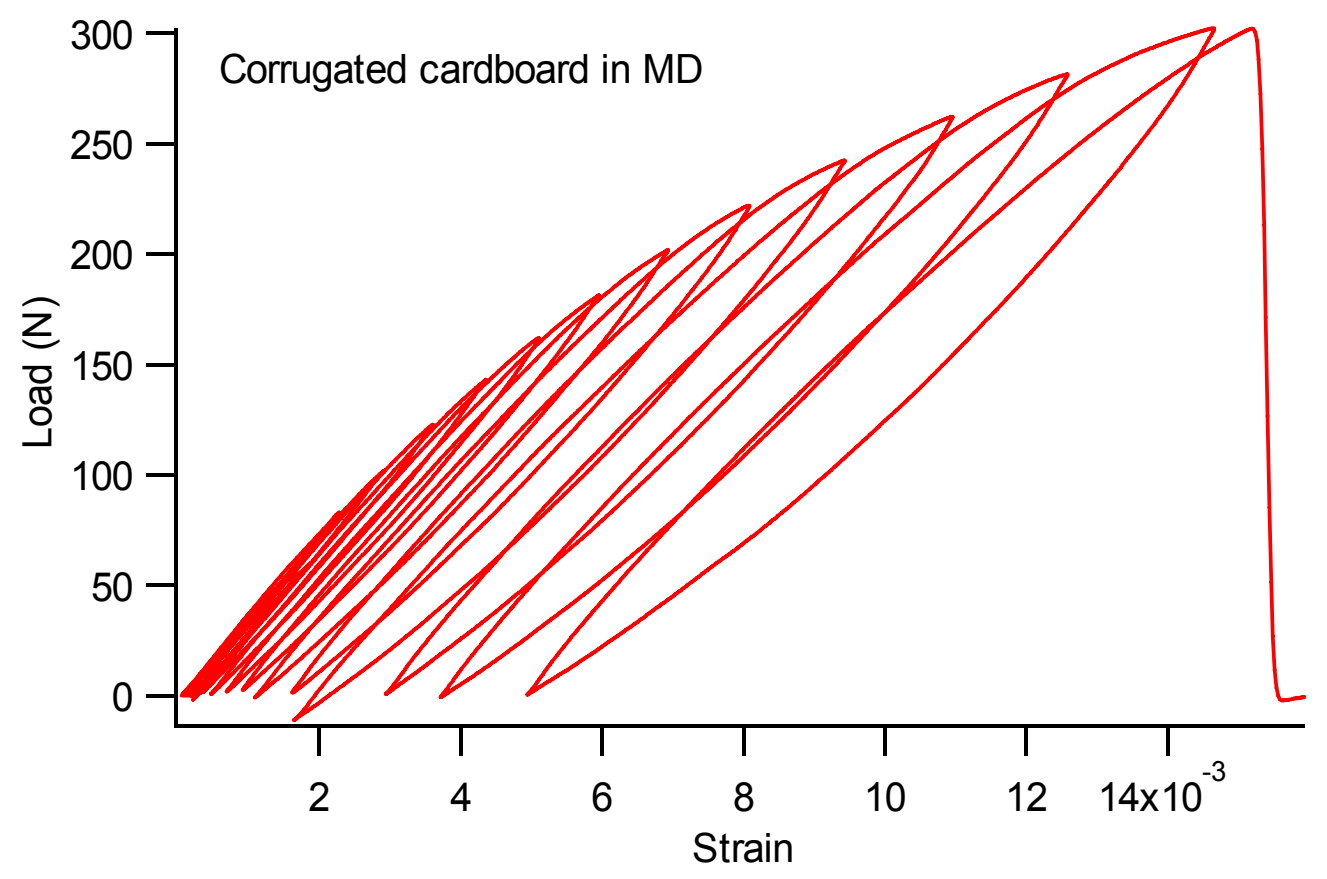



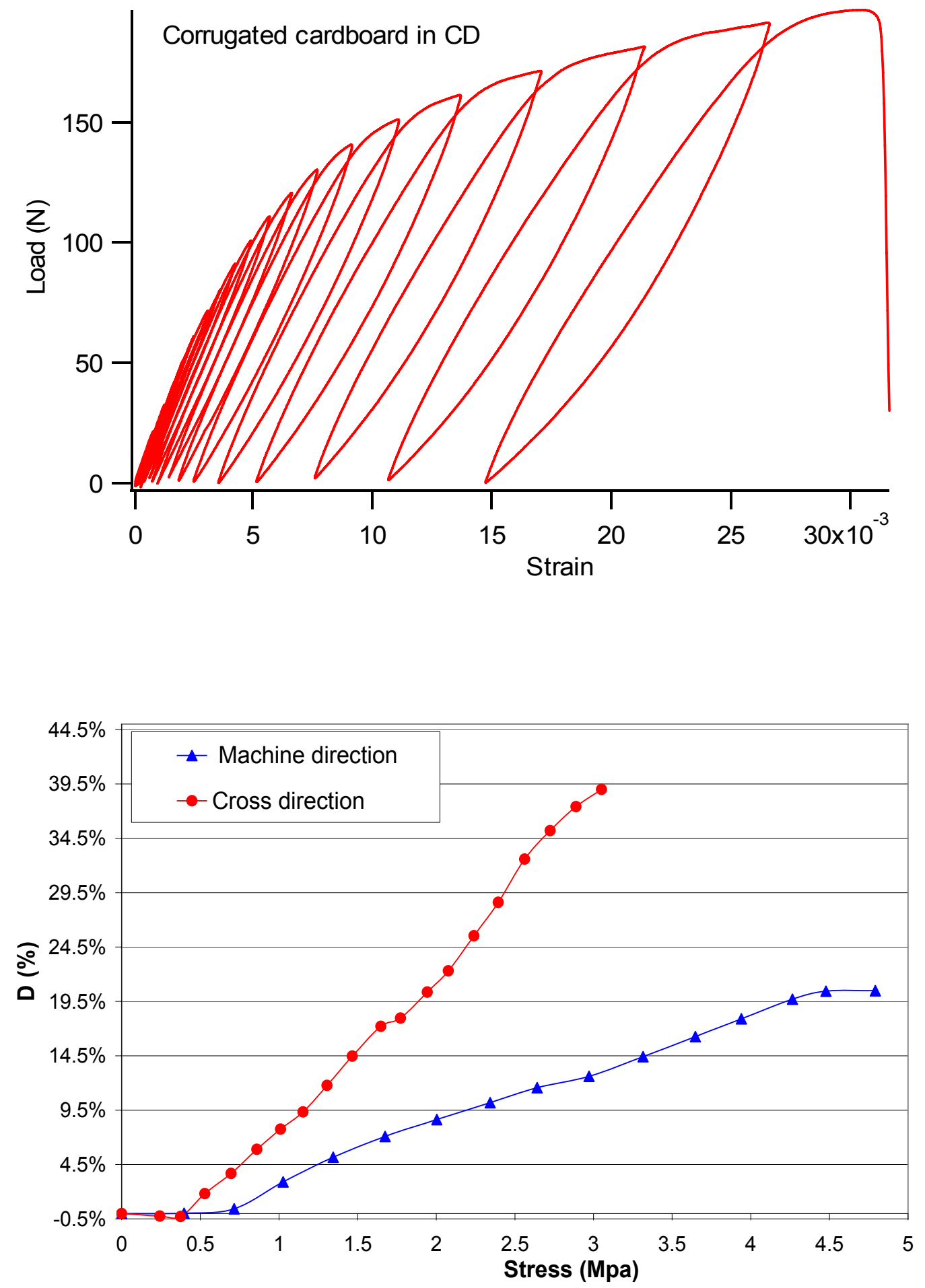
Material

$\begin{array}{llll}\text { Direction } & \text { Corrugated cardboard } & \text { Upper layer (Recto) } & \text { Lower layer (Verso) }\end{array}$

\begin{tabular}{|c|c|c|c|c|}
\hline \multicolumn{5}{|c|}{ Young Modulus (MPa) } \\
\hline MD & 644.45 & 4322.20 & 4433.48 & 5106.67 \\
\hline CD & 433.10 & 2048.27 & 2032.91 & 1962.35 \\
\hline \multicolumn{5}{|c|}{ Load (N) } \\
\hline MD & 285.35 & 134.83 & 146.81 & 123.75 \\
\hline CD & 185.79 & 60.710 & 61.87 & 43.58 \\
\hline \multicolumn{5}{|c|}{ Strain failure (\%) } \\
\hline MD & 1.71 & 1.66 & 1.83 & 1.60 \\
\hline CD & 4.12 & 3.68 & 3.16 & 3.51 \\
\hline
\end{tabular}

\begin{tabular}{lcccccc}
\hline Strain rate $\dot{\varepsilon}\left(\mathrm{s}^{-1}\right)$ & $6^{*} 10^{-5}$ & $12 * 10^{-5}$ & $6^{*} 10^{-4}$ & $12 * 10^{-4}$ & $6^{*} 10^{-3}$ & $12 * 10^{-3}$ \\
\hline Control displacement $(\mathrm{mm} / \mathrm{min})$ & 0.5 & 1 & 5 & 10 & 50 & 100 \\
\hline
\end{tabular}




\begin{tabular}{|c|c|c|c|c|c|c|c|}
\hline & \multirow{2}{*}{ Direction } & \multicolumn{6}{|c|}{ Strain rates $\dot{\varepsilon}\left(\mathrm{s}^{-1}\right)$} \\
\hline & & $6 * 10^{-5}$ & $12 * 10^{-5}$ & $6 * 10^{-4}$ & $12 * 10^{-4}$ & $6 * 10^{-3}$ & $12 * 10^{-3}$ \\
\hline \multirow{2}{*}{ 胥 } & $\begin{array}{c}\sigma_{\mathrm{f}}(\mathrm{MPa}) \\
\mathrm{MD}\end{array}$ & $36.24 \pm 2.40$ & $35.94 \pm 2.50$ & $42.77 \pm 1.54$ & $42.03 \pm 2.20$ & $43.01 \pm 3.26$ & $45.27 \pm 1.57$ \\
\hline & $\begin{array}{c}\sigma_{\mathrm{f}}(\mathrm{MPa}) \\
\mathrm{CD}\end{array}$ & $14.72 \pm 0.93$ & $15.77 \pm 1.27$ & $17.09 \pm 0.61$ & $16.95 \pm 0.55$ & $17.28 \pm 1.10$ & $17.949 \pm 0.81$ \\
\hline \multirow{2}{*}{ 总 } & $\begin{array}{c}\sigma_{\mathrm{f}}(\mathrm{MPa}) \\
\mathrm{MD}\end{array}$ & $36.02 \pm 1.19$ & $40.51 \pm 1.95$ & $41.61 \pm 0.71$ & $43.01 \pm 1.87$ & $44.24 \pm 1.92$ & $43.86 \pm 2.12$ \\
\hline & $\begin{array}{c}\sigma_{\mathrm{f}}(\mathrm{MPa}) \\
\mathrm{CD}\end{array}$ & $15.15 \pm 0.85$ & $15.86 \pm 0.80$ & $16.42 \pm 0.74$ & $17.85 \pm 1.22$ & $18.02 \pm 0.70$ & $19.76 \pm 0.56$ \\
\hline \multirow{2}{*}{$\overline{0}$} & $\begin{array}{c}\sigma_{\mathrm{f}}(\mathrm{MPa}) \\
\mathrm{MD}\end{array}$ & $41.02 \pm 2.32$ & $42.35 \pm 2.53$ & $45.61 \pm 1.62$ & $46.83 \pm 0.92$ & $46.12 \pm 2.19$ & $48.97 \pm 3.58$ \\
\hline & $\begin{array}{c}\sigma_{\mathrm{f}}(\mathrm{MPa}) \\
\mathrm{CD}\end{array}$ & $15.83 \pm 0.75$ & $16.24 \pm 0.65$ & $16.67 \pm 0.51$ & $17.52 \pm 0.96$ & $18.82 \pm 0.44$ & $18.83 \pm 065$ \\
\hline
\end{tabular}

\begin{tabular}{|c|c|c|c|c|c|c|c|}
\hline & & & & Strain $r$ & $\dot{\varepsilon}\left(\mathrm{s}^{-1}\right)$ & & \\
\hline & Direction & $6 * 10^{-5}$ & $12 * 10^{-5}$ & $6 * 10^{-4}$ & $12 * 10^{-4}$ & $6 * 10^{-3}$ & $12 * 10^{-3}$ \\
\hline & $\begin{array}{c}\mathrm{E}(\mathrm{MPa}) \\
\mathrm{MD}\end{array}$ & $4718 \pm 125$ & $4868 \pm 112$ & $5265 \pm 166$ & $5191 \pm 83$ & $5292 \pm 186$ & $5408 \pm 99$ \\
\hline$\simeq$ & $\begin{array}{c}\mathrm{E}(\mathrm{MPa}) \\
\mathrm{CD}\end{array}$ & $1944 \pm 148$ & $2017 \pm 77$ & $2123 \pm 68$ & $2137 \pm 64$ & $2213 \pm 76$ & $2255 \pm 79$ \\
\hline$\%$ & $\begin{array}{c}\mathrm{E} \\
\mathrm{MD} \\
\mathrm{MDa}\end{array}$ & $5086 \pm 184$ & $5065 \pm 190$ & $4952 \pm 207$ & $5468 \pm 129$ & $5323 \pm 125$ & $5246 \pm 380$ \\
\hline$>$ & $\begin{array}{cl}E & (\mathrm{MPa}) \\
& \mathrm{CD}\end{array}$ & $2056 \pm 99$ & $2062 \pm 108$ & $2072 \pm 73$ & $2306 \pm 66$ & $2389 \pm 83$ & $2518 \pm 84$ \\
\hline & $\begin{array}{c}\mathrm{E}(\mathrm{MPa}) \\
\mathrm{MD}\end{array}$ & $5122 \pm 168$ & $5155 \pm 244$ & $5336 \pm 198$ & $5609 \pm 194$ & $5771 \pm 121$ & $6259 \pm 185$ \\
\hline 3 & $\begin{array}{cl}\mathrm{E} & (\mathrm{MPa}) \\
& \mathrm{CD}\end{array}$ & $2067 \pm 78$ & $2203 \pm 54$ & $2223 \pm 82$ & $2291 \pm 124$ & $2355 \pm 108$ & $2529 \pm 146$ \\
\hline
\end{tabular}


Figure 1: Principal directions of paperboard

Figure 2: Principal directions of corrugated cardboard

Figure 3: Video tensile test

Figure 4: Tensile curves of paperboard in his in-plane directions

Figure 5: Tensile curves of cardboard in his in-plane directions

Figure 6: Stress-strain curves of the paperboard Well in MD according to $\dot{\varepsilon}$ solicitation Figure 7: Stress-strain curves of the paperboard Well in CD according to $\dot{\varepsilon}$ solicitation

Figure 8: Stress-strain curves of the paperboard Recto in MD according to $\dot{\varepsilon}$ solicitation

Figure 9: Stress-strain curves of the paperboard Recto in CD according to $\dot{\varepsilon}$ solicitation

Figure 10: Loading-unloading-held tensile response of the paperboard Verso in MD

Figure 11: Loading-unloading-held tensile response of the paperboard Recto in CD

Figure 12: Strain covers of paperboard according to time

Figure 13: Machine direction cyclic loading of the paperboard Verso

Figure 14: Cross direction cyclic loading of the paperboard Verso

Figure 15: Evolution of the parameter D

Figure 16: Coating on the Recto paperboard

Figure 17: Coating on the Well paperboard

Figure 18: Tensile device under SEM

Figure 19: Cross direction relaxation tensile test

Figure 20: Machine direction relaxation tensile test

Figure 21: Failure photography of paperboard in cross direction

Figure 22: Follow-up of a paperboard crack in the cross direction

Figure 23: Failure photography of paperboard in machine direction

Figure 24: Damage mechanisms of paperboard 
Figure 25: Machine direction cyclic loading of the corrugated cardboard

Figure 26: Cross direction cyclic loading of the corrugated cardboard

Figure 27: Evolution of the parameter D of the corrugated cardboard

Table 1: Elastic and failure parameters of the materials

Table 2: Range strain rates

Table 3: Evolution of the failure stress (MPa) according to strain rate request

Table 4: Evolution of the Young modulus $(\mathrm{MPa})$ according to strain rate request 